\title{
Assessing Beneficiaries' Healthcare Satisfaction under National Health Insurance in Dar es Salaam Region, Tanzania
}

\author{
Yohana Andeshi Kiyoya ${ }^{1}$
}

\begin{abstract}
This research is based on an empirical study of NHIF beneficiaries on the quality of healthcare received under the scheme. It investigates the extent of healthcare satisfaction as perceived by principal beneficiaries on various factors influencing healthcare, and examined challenges facing the scheme as per beneficiaries' opinion. This research used survey method for data collection. The analysis is done using primary data from the questionnaire, which were distributed to 152 NHIF beneficiaries (employee) at the National Identification Authority (NIDA) in October 2018. Data collection instrument included a Google-based questionnaire with closed questions. Data were analyzed quantitatively using descriptive statistics (Quantitative descriptive study design). The study found unsatisfactory results on some of the services given by the scheme such as a number of dependents covered, the range of diseases covered, time for treatment intervention, time to wait for diagnostic tests, an appointment with the specialists, and time to retrieve files. It also examined budget constraints, public awareness, and acceptance of the scheme, corruption, and embezzlement as the challenge facing the scheme.
\end{abstract}

\section{Keywords:}

beneficiaries' satisfaction; financing healthcare; NHIF

\section{Introduction}

Over the past few decades, the need to reform health care services in most African countries including other low-and-middleincome countries have raised the inequities in availability to affordable health care. The increase in reliance on out-of-pocket payments and private organized health services has culminated into health care attained on the ground of one's ability to pay; the situation intensifies the risk of low-income groups to become more susceptible due to failure to access better health (Mcintyre et al., 2008).

Provision of health care services in Tanzania is through the public and private sector. The central government through the Ministry of Health and Social Welfare is the key provider of the services through public-owned hospitals in the country. Alongside the public hospitals, health services were also provided by the not-for-profit organization and FaithBased Organizations. However, because of income inequalities, access to health depends on the income status of the patients or the family. Effort attempted to address the equity challenges arising from this fragmentation and what remains to be done to promote universal coverage. Mcintyre et al., (2008) conducted a study with the intention to examine how the United Republic of Tanzania, Ghana,

\footnotetext{
${ }^{1}$ Ministry of Home Affairs Tanzania

Email: andeshiy@yahoo.com
} 
and South Africa endeavor to move beyond fragmentations toward embracing universal health coverage. The study indicates how these countries have been transforming their health systems from being fragmented to regaining lost equity in health services delivery.

In the course of reforming the healthcare system in the country, the government established the National Health Insurance Fund (NHIF). Even though, the NHIF Health scheme is spread all over the country; its coverage in terms of the population who are benefiting from its services is absolutely low. As of October 2017, NHIF, which predominantly concern with giving health insurance strictly for the formal sector, had over 750,000 primary members and approximately 3.5 million total beneficiaries. On the other hand, over 2.1 million rural residents and informal households are accommodated to a community health fund (CHF)-district level schemes with no set of a benefits package or uniform contribution rates Prabhakaran and Arin (2017).

Although enrolment with the NHIF tends to increase, scholars warn that the rise is triggered by the scheme being compulsory and not basing on the ground of its efficiency referred to severe dissatisfaction complaints raised by members on the quality of services provided (Mtei, 2005). Furthermore, various authors have explained their thoughts regarding the durability and sustainability of the Fund where over $95 \%$ of enrollees contribute below 10,000 Tanzania shillings which raise the question of sustainability (Msimbe, 2005; Mtei \& Josephine, 2010; Mtei \& Makwaia, 2014).

However, studies indicate that implementation of NHIF in Tanzania faces various challenges affecting its ability to deliver quality services to citizens (National Audit Office, 2008; Ernest, 2011; National Bureau of Statistics et al., 2016; and WHO, 2016). Ministry of Health and Social Welfare (MOHSW) (2013) reported concerning insufficient laboratory services and other equipment such as X-rays machines, CT scan machine, and MRI machines. This inadequate service provision compels people to search for the same services to other private facilities not accredited by the scheme at their own cost Boniphace (2016).

Meeting NHIF beneficiaries' satisfaction is the concerns which really need to be addressed when assessing the effectiveness of the scheme. Anderson (1973) said that customers strive to escape dissonance by altering the perceptions on the product, so as to attract it closer to their prior conceived expectations. Similarly, the consumer can shrink the missing link between expectations and performance by dismantling expectations so as to be in harmony with product's perceived performance, while raising the degree of satisfaction through the relative importance of experimental disconfirmation (Olson \&Dover, 1979). On the other hand, Anderson (1973) posits that dissatisfaction can hardly happen unless the assessment procedures are preceded by the consumers' negative expectations. In the light of these contemporary developments and challenges facing the scheme, the concern for assessing beneficiaries' level of healthcare satisfaction under NHIF become paramount.

\section{Methods \\ Study design}

This study used a quantitative research design intended to ask a number of respondents the same question and mobilize data that helped to show patients' level of healthcare satisfaction under NHIF. Quantitative research design assisted a researcher to grasp the perception of NHIF members on the service provided by the scheme if is promising or not. Further, the approach is pointed as the design assisted this study to be in a position to examine the problem at a point in time without taking a long time. The advantage of quantitative study design relies on its ability to help to understand the perceptions of NHIF subscribers on the scheme on issues that cannot be clearly observed. 


\section{Area of the study}

The study was executed in the Dar es Salaam region, Tanzania involving one public institution (National Identification Authority) where NHIF beneficiaries were randomly selected. The selection of this single region is due to the fact that the area possesses numerous NHIF accredited facilities. Further, the region is rich in communication facilities helpful for a researcher during data collection from members compared to other regions. In this case, the study portrayed the reality of how effective NHIF functions in services delivery.

\section{Target Population and Sample Size}

The total sampleincluded 152 respondents from the National Identification Authority employees. All were principal beneficiaries of the scheme and have experience with service offered and aware of accredited facilities either public or private. In determining the sample size a table for determining the number of samples from a particular population developed from Isaak and Michael (Sugiyono, 2011 ), for an error rate of $5 \%$ so that it can obtain $95 \%$ confidence was used.

\section{Data Collection Methods}

Data were collected using two sources namely Primary and Secondary sources. The methodology in primary data collection was questionnaires; secondary data was collected via documentation or documentary review. Data included socio-demographic information such as age, sex, education level, marital status, designation, and working experience. The questionnaire composed of 32 items were used to assess the level of beneficiaries satisfactions on the five-point Likert scale from Very dissatisfied $=1$, somewhat dissatisfied $=2$, somewhat satisfied $=3$, satisfied $=4$, and very satisfied $=5$. Details regarding the question were properly articulated to the responded before filling the questionnaire.

\section{Data Processing and Analysis Technique}

Statistical Package for Social Science (SPSS), classifying, means and tabulation of data were used. Frequency, percentage, and mean score, and the standard deviation was used to analyze various characteristics of the sample population such as sex, marital status, education, and working experience, designation, and type of health facility.

\section{Results and Discussion}

This section is devoted to present all the statistical findings on the factors concerning the level of beneficiaries' satisfaction with healthcare delivery under the NHIF. It also further discusses the findings on the factors perceived to challenge the effectiveness of the scheme in delivering quality services that meet customer expectations.

The objective of this study was to establish a profile of the beneficiaries' level of satisfaction on healthcare services provided under the scheme in Dar es Salaam region, Tanzania. It also intended to examine the challenges the scheme is encountering in ensuring the provision of quality healthcare to the subscribers. Two questions were also devised so as to assist in reaching these critical objectives. First, What is the level of beneficiaries' healthcare satisfaction under NHIF? Second, What is the challenges that NHIF face in the course of ensuring the provision of healthcare/medical services?

The study was implemented in Dar es Salaam region, Tanzania involving one public institution which was deliberately selected by the researcher. Data was collected from 152 employees with the status of principal membership to the scheme covering various destinations such as professional, nonprofessional and administrators. The data mobilized were then analyzed using SPSS where a percentage, frequency distribution. 
Table 1.

Socio-demographic characteristics of the respondents

\begin{tabular}{|c|c|c|c|}
\hline & Variable & Frequency & Percentage \\
\hline \multirow[t]{4}{*}{ Gender } & Male & 98 & 64.5 \\
\hline & Female & 54 & 35.5 \\
\hline & Total & 152 & 100 \\
\hline & Divorced & 3 & 2 \\
\hline \multirow{3}{*}{$\begin{array}{l}\text { Marital } \\
\text { Status }\end{array}$} & Married & 80 & 52.6 \\
\hline & Single & 69 & 45.4 \\
\hline & Total & 152 & 100 \\
\hline \multirow[t]{5}{*}{ Age } & $20-29$ & 45 & 28.3 \\
\hline & $30-39$ & 102 & 67.1 \\
\hline & $40-49$ & 6 & 3.9 \\
\hline & 50 and Above & 1 & 0.7 \\
\hline & Total & 152 & 100 \\
\hline \multirow[t]{6}{*}{ Education } & $\begin{array}{l}\text { Certificate of } \\
\text { Education }\end{array}$ & 1 & 0.7 \\
\hline & $\begin{array}{l}\text { College } \\
\text { Diploma }\end{array}$ & 19 & 12.5 \\
\hline & Doctoral Degree & 1 & 0.7 \\
\hline & Master's Degree & 31 & 20.4 \\
\hline & Bachelor Degree & 100 & 65.8 \\
\hline & Total & 152 & 100 \\
\hline \multirow{5}{*}{$\begin{array}{l}\text { Working } \\
\text { experience }\end{array}$} & $1-5$ & 79 & 52 \\
\hline & $6-10$ & 62 & 40.8 \\
\hline & $11-15$ & 6 & 3.6 \\
\hline & 16 and above & 5 & 3.3 \\
\hline & Total & 152 & 100 \\
\hline \multirow[t]{4}{*}{ Designation } & Administrator & 28 & 18.4 \\
\hline & $\begin{array}{l}\text { Non- } \\
\text { Professional }\end{array}$ & 12 & 7.9 \\
\hline & Professional & 112 & 73.9 \\
\hline & Total & 152 & 100 \\
\hline
\end{tabular}

Source: Field Survey, 2018

\section{Assessing Beneficiaries' Level of Healthcare Satisfactions}

The study had sought to assess the factors influencing beneficiaries' level of satisfaction on the services provided under NHIF. The six (6) factors included were Availability of drugs, Availability of diagnostic equipment/ tests, Availability of healthcare workers, Staff responsiveness, File or record handling, and Services covered by NHIF.

\section{Availability of Drugs}

The perception of the respondents on the number of drugs received from an accredited healthcare facility showed that the majority 58(38.2\%) were somewhat satisfied. Asked whether they were satisfied with waiting time to visit the doctor for a medical prescription it revealed that were somewhat satisfied with time 47(30.9\%). Respondents also reported being satisfied with the factor of quality of drugs $49(32.8 \%)$. The study asked whether participants were satisfied with if the pharmacist explained drug doses, the response showed that the majority were satisfied $51(33.6 \%)$. Time spent to receive the drug from the pharmacy was perceived to be somewhat satisfactory by the majority. The overall mean score for this factor on the availability of drugs was $\mathrm{M}=3.05$ out of 5 .

Despite the fact that the availability of the drug is the most critical challenge facing most of the healthcare financing system. This study finds that beneficiaries are somewhat satisfied with how this aspect is being implemented under NHIF. However, much effort need to be initiated so to increase the availability of drugs to meet the need of the customers from time spent to get medicines and the number of drugs received i.e the scheme should rethink of increase the list of medicines. Previous studies also reported how the beneficiaries perceived accessibility to drugs as a bit challenge calling for serious actions by the concerning parts Marwa (2016); Bayarsaikhan \& Laurent(2016); and Mwinuka \& Aggrey (2016) all discovered the persistent of a drug shortage that affects beneficiaries level of satisfaction. On contrary, a study by Boniphace (2016) found that accreditation that was implemented by NHIF has improved the availability of drugs in the accredited health facilities at the high level resulting in improved health delivery to the members.

\section{Availability of diagnostic equipment/tests}

For waiting time for the diagnostic appointment, the good number of beneficiaries reported being somewhat satisfied $45(29.6 \%)$. Responding on the statement regarding 
Table 2.

Scores of beneficiaries' satisfaction assessment with drugs

\begin{tabular}{|c|c|c|c|c|c|}
\hline Availability of drugs & Scale & $\mathbf{F}$ & Percentage & Mean & SD \\
\hline \multirow{6}{*}{$\begin{array}{l}\text { The number of Drugs } \\
\text { Received }\end{array}$} & Very dissatisfied & 11 & 7.2 & & \\
\hline & Somewhat dissatisfied & 26 & 17.1 & & \\
\hline & Somewhat satisfied & 58 & 38.2 & & \\
\hline & Satisfied & 44 & 28.9 & & \\
\hline & Very satisfied & 13 & 8.9 & & \\
\hline & Total & 152 & 100 & 3.14 & 1.038 \\
\hline \multirow{6}{*}{$\begin{array}{l}\text { Waiting time to visit the } \\
\text { Doctor }\end{array}$} & Very dissatisfied & 25 & 16.4 & & \\
\hline & Somewhat dissatisfied & 38 & 25 & & \\
\hline & Somewhat satisfied & 47 & 30.9 & & \\
\hline & Satisfied & 36 & 23.7 & & \\
\hline & Very satisfied & 6 & 3.9 & & \\
\hline & Total & 152 & 100 & 2.74 & 1.114 \\
\hline \multirow[t]{6}{*}{ Assured Quality of Drugs } & Very dissatisfied & 15 & 9.9 & & \\
\hline & Somewhat dissatisfied & 33 & 21.7 & & \\
\hline & Somewhat satisfied & 44 & 28.9 & & \\
\hline & Satisfied & 49 & 32.2 & & \\
\hline & Very satisfied & 11 & 7.2 & & \\
\hline & Total & 152 & 100 & 3.05 & 1.109 \\
\hline \multirow{6}{*}{$\begin{array}{l}\text { Pharmacists explained clearly } \\
\text { drug doses }\end{array}$} & Very dissatisfied & 16 & 10.5 & & \\
\hline & Somewhat dissatisfied & 22 & 14.5 & & \\
\hline & Somewhat satisfied & 44 & 28.9 & & \\
\hline & Satisfied & 51 & 33.6 & & \\
\hline & Very satisfied & 19 & 12.5 & & \\
\hline & Total & 152 & 100 & 3.23 & 1.165 \\
\hline \multirow[t]{7}{*}{ Waiting time to receive drugs } & Very dissatisfied & 15 & 9.9 & & \\
\hline & Somewhat dissatisfied & 26 & 17.1 & & \\
\hline & Somewhat satisfied & 54 & 35.5 & & \\
\hline & Satisfied & 46 & 30.3 & & \\
\hline & Very satisfied & 11 & 7.2 & & \\
\hline & Total & 152 & 100 & 3.08 & 1.076 \\
\hline & Mean score & & & 3.05 & 1.100 \\
\hline
\end{tabular}

Source: Field Survey, 2018

waiting time in the waiting room the majority of the participants were somewhat satisfied $47(30.9 \%)$. Respondents were also asked about diagnostic services or tests offered and the result indicated that the majority were somewhat satisfied 52(34.2\%). However, when asked about whether participants were satisfied with the explanation for diagnostic tests, results, and treatment, the majority said to be satisfied 52(34.2\%). The overall mean score for the factor of availability of diagnostic test was $\mathrm{M}=2.90$ out of 5 .

Diagnostic services are among the important components for effective healthcare financing system. Insurance schemes strive to offer the best it can on diagnostic so as to meet customer demands for healthcare and address the problem of out-of-pocket payment for healthcare. Thompson, et al., 2011 said that diagnostic tests assist at least threequarters of all patients' conclusions reached in healthcare delivery. Being an indispensable factor for effective healthcare delivery meeting beneficiaries' satisfaction on this is of great impetus. The challenge facing NHIF often time is offering the important tests as may be required by the subscribers and quite often customers have been complaining about time 
Table 3.

Scores of beneficiaries' satisfaction assessment with diagnostic services

\begin{tabular}{|c|c|c|c|c|c|}
\hline Availability of diagnostic services & Scale & $\mathbf{F}$ & Percentage & Mean & SD \\
\hline \multirow[t]{6}{*}{ Availability of diagnostic appointment } & Very dissatisfied & 13 & 8.6 & & \\
\hline & Somewhat dissatisfied & 40 & 26.3 & & \\
\hline & Somewhat satisfied & 51 & 3.6 & & \\
\hline & Satisfied & 38 & 25 & & \\
\hline & Very satisfied & 10 & 6.6 & & \\
\hline & Total & 152 & 100 & 2.95 & 1.06 \\
\hline \multirow{6}{*}{$\begin{array}{l}\text { Waiting time for the diagnostic } \\
\text { appointment }\end{array}$} & Very dissatisfied & 22 & 14.5 & & \\
\hline & Somewhat dissatisfied & 41 & 27 & & \\
\hline & Somewhat satisfied & 45 & 29.6 & & \\
\hline & Satisfied & 37 & 24.3 & & \\
\hline & Very satisfied & 7 & 4.6 & & \\
\hline & Total & 152 & 100 & 2.78 & 1.111 \\
\hline \multirow[t]{6}{*}{ Waiting time in the waiting room } & Very dissatisfied & 25 & $\overline{16.4}$ & & \\
\hline & Somewhat dissatisfied & 39 & 25.7 & & \\
\hline & Somewhat satisfied & 47 & 30.9 & & \\
\hline & Satisfied & 35 & 23 & & \\
\hline & Very satisfied & 6 & 3.9 & & \\
\hline & Total & 152 & 100 & 2.72 & 1.11 \\
\hline \multirow[t]{6}{*}{ Diagnostic tests offered } & Very dissatisfied & 19 & 12.5 & & \\
\hline & Somewhat dissatisfied & 26 & 17.1 & & \\
\hline & Somewhat satisfied & 52 & 34.2 & & \\
\hline & Satisfied & 46 & 30.3 & & \\
\hline & Very satisfied & 9 & 5.9 & & \\
\hline & Total & 152 & 100 & 3.00 & 1.104 \\
\hline \multirow{7}{*}{$\begin{array}{l}\text { Explanation of results, tests, and } \\
\text { treatment }\end{array}$} & Very dissatisfied & 20 & 13.2 & & \\
\hline & Somewhat dissatisfied & 26 & 17.1 & & \\
\hline & Somewhat satisfied & 43 & 28.3 & & \\
\hline & Satisfied & 52 & 34.2 & & \\
\hline & Very satisfied & 11 & 7.2 & & \\
\hline & Total & 152 & 100 & 3.05 & 1.155 \\
\hline & Mean score & & & 2.90 & 1.108 \\
\hline
\end{tabular}

Source: Field Survey, 2018

delay for the appointment and unreliable diagnostic equipment.

MOHSW (2013) and Boniphace (2016) uncovered an important point on this factor reporting insufficient laboratory services, and other equipment such as $\mathrm{x}$ rays machines, $\mathrm{CT}$ scan machine, and MRI machines. Under these circumstances, beneficiaries under NHIF are compelled too much for the same services to other private facilities not accredited by the scheme using out-of-pocket payment. This becomes a clear indication that beneficiaries feel dissatisfied with services provided on the aspect of diagnostic services and therefore improvement needs to be done.

\section{Availability of healthcare workers}

The beneficiaries' perception on the availability of healthcare workers by using several items was measured. Most of the respondents reported being somewhat satisfied with the time spent to wait for a medical prescription from the doctor $47(30.9 \%)$. Responding on the statement time spent to wait for treatment intervention i.e. surgery and other procedures and time spent to wait for doctor diagnostic test appointment response was somewhat dissatisfactory $51(33.6 \%)$ and $50(32.9 \%)$ respectively. The response on the statement about nurses at accredited healthcare facility and doctors or general healthcare 
Table 4.

Scores of beneficiaries' satisfaction assessment with healthcare workers

\begin{tabular}{|c|c|c|c|c|c|}
\hline $\begin{array}{c}\text { Availability } \\
\text { of healthcare workers }\end{array}$ & Scale & $\mathbf{F}$ & Percentage & Mean & SD \\
\hline \multirow{6}{*}{$\begin{array}{l}\text { Time spent to wait for medicine } \\
\text { prescription from Doctor }\end{array}$} & Very dissatisfied & 20 & 13.2 & \multirow{11}{*}{2.74} & \multirow{11}{*}{1.070} \\
\hline & Somewhat dissatisfied & 45 & 29.6 & & \\
\hline & Somewhat satisfied & 47 & 30.9 & & \\
\hline & Satisfied & 34 & 22.4 & & \\
\hline & Very satisfied & 6 & 3.9 & & \\
\hline & Total & 152 & 100 & & \\
\hline \multirow{6}{*}{$\begin{array}{l}\text { Time spent to wait for treatment } \\
\text { intervention e.g. surgery and other } \\
\text { procedures }\end{array}$} & Very dissatisfied & 21 & 13.8 & & \\
\hline & Somewhat dissatisfied & 51 & 33.6 & & \\
\hline & Somewhat satisfied & 48 & 31.6 & & \\
\hline & Satisfied & 24 & 15.8 & & \\
\hline & Very satisfied & 8 & 5.3 & & \\
\hline & Total & 152 & 100 & \multirow[t]{6}{*}{2.65} & \multirow[t]{6}{*}{1.069} \\
\hline \multirow{6}{*}{$\begin{array}{l}\text { Time spent to wait for Doctor } \\
\text { diagnostic test }\end{array}$} & Very dissatisfied & 21 & 13.8 & & \\
\hline & Somewhat dissatisfied & 50 & 32.9 & & \\
\hline & Somewhat satisfied & 46 & 30.3 & & \\
\hline & Satisfied & 28 & 18.4 & & \\
\hline & Very satisfied & 7 & 4.6 & & \\
\hline & Total & 152 & 100 & \multirow[t]{6}{*}{2.67} & \multirow[t]{6}{*}{1.072} \\
\hline \multirow{6}{*}{$\begin{array}{l}\text { Number of nurses at Accredited } \\
\text { Healthcare facility }\end{array}$} & Very dissatisfied & 26 & 17.1 & & \\
\hline & Somewhat dissatisfied & 36 & 23.7 & & \\
\hline & Somewhat satisfied & 52 & 34.2 & & \\
\hline & Satisfied & 30 & 19.7 & & \\
\hline & Very satisfied & 8 & 5.3 & & \\
\hline & Total & 152 & 100 & \multirow[t]{6}{*}{2.72} & \multirow[t]{6}{*}{1.122} \\
\hline \multirow{6}{*}{$\begin{array}{l}\text { Doctors or general healthcare } \\
\text { practitioners at the accredited } \\
\text { healthcare facility }\end{array}$} & Very dissatisfied & 22 & 14.5 & & \\
\hline & Somewhat dissatisfied & 37 & 24.3 & & \\
\hline & Somewhat satisfied & 48 & 31.6 & & \\
\hline & Satisfied & 38 & 25 & & \\
\hline & Very satisfied & 7 & 4.6 & & \\
\hline & Total & 152 & 100 & \multirow[t]{6}{*}{2.81} & \multirow[t]{6}{*}{1.108} \\
\hline \multirow[t]{7}{*}{ Appointment with Specialists } & Very dissatisfied & 27 & 17.8 & & \\
\hline & Somewhat dissatisfied & 47 & 30.9 & & \\
\hline & Somewhat satisfied & 36 & 23.7 & & \\
\hline & Satisfied & 27 & 17.8 & & \\
\hline & Very satisfied & 15 & 9.9 & & \\
\hline & Total & 152 & 100 & \multirow{2}{*}{$\begin{array}{l}2.71 \\
2.72\end{array}$} & 1.232 \\
\hline & Mean Score & & & & 1.112 \\
\hline
\end{tabular}

Source: Field Survey, 2018

practitioners was somewhat satisfactory to the majority of the respondents $52(34.2 \%)$ and $48(31.6 \%)$ respectively. Respondents show somewhat dissatisfied on the factor of appointment with the specialist 47(30.9\%). The mean score was $\mathrm{M}=2.72$ out of 5 .

This finding is not surprising at all. The concern for healthcare workers scarcity is at the global agenda and is reported as most of the intractable problems facing the healthcare system. In this study, the findings revealed with no doubt that majority of the respondents were not satisfied in some statement about the availability of services from healthcare workers measured on time spend to reach the physicians. This sends a picture that healthcare or accredited health facility is understaffed so the queue for doctor consultation is long, 
appointments with the doctor take time to be fulfilled. This deviates beneficiaries expectations as for them could wish to get services at the real time that means the time service is required. But this can't be possible if facilities are running short of healthcare workers. This finding is compatible with previous studies indicating the challenges of healthcare workers as among the impending factor to realize effective healthcare under NHIF (Mershed \& Reinhard, 2012) and (Marwa, 2016).

\section{Staff responsiveness}

Staff responsiveness has a great influence on patients' satisfaction as it portrays how customers are treated by healthcare providers. The findings portrayed that majority of

Table 5.

Scores of beneficiaries' satisfaction assessment with staff responsiveness

\begin{tabular}{|c|c|c|c|c|c|}
\hline Staff Responsiveness & Scale & $\mathbf{F}$ & Percentage & Mean & SD \\
\hline \multirow{6}{*}{$\begin{array}{l}\text { The doctor explained diseases in an } \\
\text { understandable way }\end{array}$} & Very dissatisfied & 15 & 9.9 & & \\
\hline & Somewhat dissatisfied & 38 & 25 & & \\
\hline & Somewhat satisfied & 41 & 27 & & \\
\hline & Satisfied & 43 & 28.3 & & \\
\hline & Very satisfied & 15 & 9.9 & & \\
\hline & Total & 152 & 100 & 3.03 & 1.153 \\
\hline \multirow{6}{*}{$\begin{array}{l}\text { The doctor spent enough time with } \\
\text { the patient }\end{array}$} & Very dissatisfied & 18 & 11.8 & & \\
\hline & Somewhat dissatisfied & 38 & 25 & & \\
\hline & Somewhat satisfied & 40 & 26.3 & & \\
\hline & Satisfied & 44 & 28.9 & & \\
\hline & Very satisfied & 12 & 7.9 & & \\
\hline & Total & 152 & 100 & 2.96 & 1.156 \\
\hline \multirow{6}{*}{$\begin{array}{l}\text { Pharmacists explained drug doses } \\
\text { with courtesy and respect }\end{array}$} & Very dissatisfied & 13 & 8.6 & & \\
\hline & Somewhat dissatisfied & 36 & 23.7 & & \\
\hline & Somewhat satisfied & 50 & 32.9 & & \\
\hline & Satisfied & 40 & 26.3 & & \\
\hline & Very satisfied & 13 & 8.6 & & \\
\hline & Total & 152 & 100 & 3.03 & 1.091 \\
\hline \multirow{6}{*}{$\begin{array}{l}\text { Pharmacists spent enough time with } \\
\text { patients }\end{array}$} & Very dissatisfied & 14 & 9.2 & & \\
\hline & Somewhat dissatisfied & 44 & 28.9 & & \\
\hline & Somewhat satisfied & 45 & 29.6 & & \\
\hline & Satisfied & 39 & 25.7 & & \\
\hline & Very satisfied & 10 & 6.6 & & \\
\hline & Total & 152 & 100 & 2.91 & 1.085 \\
\hline \multirow{6}{*}{$\begin{array}{l}\text { Doctor involved patient in decision } \\
\text { making about the treatment needed } \\
\text { (Patient autonomy) }\end{array}$} & Very dissatisfied & 26 & 17.1 & & \\
\hline & Somewhat dissatisfied & 39 & 25.7 & & \\
\hline & Somewhat satisfied & 34 & 22.4 & & \\
\hline & Satisfied & 42 & 27.6 & & \\
\hline & Very satisfied & 11 & 7.2 & & \\
\hline & Total & 152 & 100 & 2.82 & 1.219 \\
\hline \multirow{7}{*}{$\begin{array}{l}\text { Received help when needed from } \\
\text { hospital staff }\end{array}$} & Very dissatisfied & 18 & 11.8 & & \\
\hline & Somewhat dissatisfied & 40 & 26.3 & & \\
\hline & Somewhat satisfied & 42 & 27.6 & & \\
\hline & Satisfied & 44 & 28.9 & & \\
\hline & Very satisfied & 8 & 5.3 & & \\
\hline & Total & 152 & 100 & 2.89 & 1.11 \\
\hline & Mean Score & & & 2.94 & 1.136 \\
\hline
\end{tabular}

Source: Field Survey, 2018 
participants $43(28.3 \%)$ were satisfied with the factor that the doctor explained diseases in an understandable way. Asked if were satisfied with whether the doctor spent enough time with patient majority $44(28.9 \%)$ were also satisfied with this statement. Majority of the respondents were somewhat satisfied with the factor that pharmacist explained drug doses with courtesy and respect and the factor of time spent by the pharmacist with patients. The score (frequency) for both factors was 50(32.9\%) and $45(29.6 \%)$ respectively. Responding to whether doctor involved patient in decision making about the treatment needed (patient autonomy) majority $42(27.6 \%)$ reported being satisfied. And finally responding to the factor whether beneficiaries received help when needed from hospital staff the majority of the participants said $44(28.9 \%)$, they were satisfied. The overall mean of the mean score for the factor of staff responsiveness was $\mathrm{M}=2.94$ out of 5 .

Much as the study revealed that majority of the patients perceived to be taken with great care as indicated being satisfied and somewhat satisfied with the statement pertaining to staff responsiveness at the health facility. For instance, being heard or opportunity to articulate their concern the patient autonomy

Table 6.

Scores of beneficiaries' satisfaction assessment with file handling

\begin{tabular}{|c|c|c|c|c|c|}
\hline File Handling & Scale & $\mathbf{F}$ & Percentage & Mean & SD \\
\hline \multirow{6}{*}{$\begin{array}{l}\text { Measures for security and } \\
\text { confidentiality of patient } \\
\text { information }\end{array}$} & Very dissatisfied & 14 & 9.2 & & \\
\hline & Somewhat dissatisfied & 33 & 21.7 & & \\
\hline & Somewhat satisfied & 44 & 28.9 & & \\
\hline & Satisfied & 50 & 32.9 & & \\
\hline & Very satisfied & 11 & 7.2 & & \\
\hline & Total & 152 & 100 & 3.07 & 1.098 \\
\hline \multirow{6}{*}{$\begin{array}{l}\text { Patient registration space and file } \\
\text { waiting time }\end{array}$} & Very dissatisfied & 25 & 16.4 & & \\
\hline & Somewhat dissatisfied & 37 & 24.3 & & \\
\hline & Somewhat satisfied & 50 & 32.9 & & \\
\hline & Satisfied & 35 & 23 & & \\
\hline & Very satisfied & 5 & 3.3 & & \\
\hline & Total & 152 & 100 & 2.72 & 1.093 \\
\hline \multirow{6}{*}{$\begin{array}{l}\text { Time is taken to retrieve the patient } \\
\text { file }\end{array}$} & Very dissatisfied & 24 & 15.8 & & \\
\hline & Somewhat dissatisfied & 48 & 31.6 & & \\
\hline & Somewhat satisfied & 42 & 27.6 & & \\
\hline & Satisfied & 32 & 21.1 & & \\
\hline & Very satisfied & 6 & 3.9 & & \\
\hline & Total & 152 & 100 & 2.66 & 1.099 \\
\hline \multirow{6}{*}{$\begin{array}{l}\text { Transparency and communication } \\
\text { between the healthcare provider and } \\
\text { patient }\end{array}$} & Very dissatisfied & 18 & 11.8 & & \\
\hline & Somewhat dissatisfied & 38 & 25 & & \\
\hline & Somewhat satisfied & 42 & 27.6 & & \\
\hline & Satisfied & 45 & 29.6 & & \\
\hline & Very satisfied & 9 & 5.9 & & \\
\hline & Total & 152 & 100 & 2.93 & 1.122 \\
\hline \multirow[t]{7}{*}{ Privacy during testing } & Very dissatisfied & 20 & 13.2 & & \\
\hline & Somewhat dissatisfied & 23 & 15.1 & & \\
\hline & Somewhat satisfied & 34 & 22.4 & & \\
\hline & Satisfied & 51 & 33.6 & & \\
\hline & Very satisfied & 24 & 15.8 & & \\
\hline & Total & 152 & 100 & 3.24 & 1.265 \\
\hline & Mean Score & & & 2.92 & 1.135 \\
\hline
\end{tabular}

Source: Field Survey, 2018 
this induces the behavior of patients taking responsibility for their health. However, the response with time can be somewhat detrimental especially for patients who require special attention in the sense which healthcare providers can't handle. These results are indispensable because, as discussed by Lavy \& Alderman (1996) it stresses the point that when the patient feels quality of health services to be low, it undermines their health-seeking behavior. For this case, it is of high priority to improving staff responsiveness so as beneficiaries of NHIF can feel well treated by healthcare providers so as to raise the level of satisfaction that converges with beneficiaries' expectations.

\section{File Handling}

This study was determined to understand how file handling contributes to patients' satisfaction at the healthcare facility. For file handling, the majority of the respondents $50(32.9 \%)$ were satisfied with the factor that measures taken for security and confidentiality of patient information. Asked about patient registration space and file waiting for time majority of the respondents 50(32.9\%) reported being somewhat satisfied, while the majority were dissatisfied with time spent to retrieve patient file $48(31.6 \%)$. Responding on the factor of transparency and communication between healthcare providers and patients, and the statement on privacy during the testing majority of the respondents felt to be satisfied with frequency score of $45(29.6 \%)$ and $51(33.6 \%)$ respectively. The overall mean for the mean score for this file handling factor was $\mathrm{M}=2.92$ out of 5 .

File handling is a very critical aspect of healthcare systems all over the world. It determines how patient information is created, filed, circulated within the health facility departments and finally destroyed when no longer needed. Because patients' information is so delicate and confidential high attention is needed from the time of its creation, utilization and when being destroyed. Patients will feel satisfied when assured that their record is taken in a serious confidential way by the concerning part. As revealed in this study beneficiaries felt to be satisfied with some aspect such as confidentiality, the transparency that means knowing what is in their file, and privacy during testing. This act as a stimulus for beneficiaries which trigger them to trust and have confidence in the treatment process they undergo. The previous study by (Mwinuka \& Aggrey, 2016) included file handling as the factor while time spent to get the file and go for treatment was used to measure for the effectiveness of file handling. The results found that SUACHF beneficiaries had a high level of file handling satisfaction than their counterpart NHIF members. Similarly, this study found that patients were satisfied by some statement as shown above but declined to be satisfied with the time spent to retrieve the patient file.

\section{Services Covered by NHIF}

Basically, it was so crucial to examine whether beneficiaries of NHIF are satisfied with various services offered by NHIF. To reach this objective a number of services were included in the questionnaire for the respondents to give opinions. Responding to the number of dependents covered, besides principal members, the results show that the majority 44 (28.9\%) were dissatisfied. On the other chain, the statement regarding healthcare services given to dependant majority of beneficiaries 49 (32.2\%) was somewhat satisfied. For drug list approved by the scheme, $45(29.6 \%)$ of the respondents reported being somewhat satisfied. Replying on the statement of rate of contribution charged and range of diseases covered by the scheme, the results showed that $50(32.9 \%)$ and $50(32.9 \%)$ of the majority were somewhat satisfied and somewhat dissatisfied respectively.

Basing on the results above, it can be viewed that beneficiaries indicated to be 
Table 7.

Scores of beneficiaries' satisfaction with services covered by NHIF

\begin{tabular}{|c|c|c|c|c|c|}
\hline $\begin{array}{l}\text { Number of Services covered by the } \\
\text { scheme }\end{array}$ & Scale & $\mathbf{F}$ & Percentage & Mean & SD \\
\hline \multirow[t]{6}{*}{ Number of dependents Covered } & Very dissatisfied & 24 & 15.8 & & \\
\hline & Somewhat dissatisfied & 44 & 28.9 & & \\
\hline & Somewhat satisfied & 35 & 23 & & \\
\hline & Satisfied & 40 & 26.3 & & \\
\hline & Very satisfied & 9 & 5.9 & & \\
\hline & Total & 152 & 100 & 2.78 & 1.175 \\
\hline \multirow[t]{6}{*}{ Healthcare provided to dependents } & Very dissatisfied & 14 & 9.2 & & \\
\hline & Somewhat dissatisfied & 34 & 22.4 & & \\
\hline & Somewhat satisfied & 49 & 32.2 & & \\
\hline & Satisfied & 46 & 30.3 & & \\
\hline & Very satisfied & 9 & 5.9 & & \\
\hline & Total & 152 & 100 & 3.01 & 1.067 \\
\hline \multirow[t]{6}{*}{ Drug list approved by the fund } & Very dissatisfied & 27 & 17.8 & & \\
\hline & Somewhat dissatisfied & 42 & 27.6 & & \\
\hline & Somewhat satisfied & 45 & 29.6 & & \\
\hline & Satisfied & 31 & 20.4 & & \\
\hline & Very satisfied & 7 & 4.6 & & \\
\hline & Total & 152 & 100 & 2.66 & 1.127 \\
\hline \multirow[t]{6}{*}{ Rate of contribution charged } & Very dissatisfied & 20 & 13.2 & & \\
\hline & Somewhat dissatisfied & 35 & 23 & & \\
\hline & Somewhat satisfied & 50 & 32.9 & & \\
\hline & Satisfied & 37 & 24.3 & & \\
\hline & Very satisfied & 10 & 6.6 & & \\
\hline & Total & 152 & 100 & 2.88 & 1.121 \\
\hline \multirow{7}{*}{$\begin{array}{l}\text { The range of diseases covered by the } \\
\text { scheme }\end{array}$} & Very dissatisfied & 27 & 17.8 & & \\
\hline & Somewhat dissatisfied & 50 & 32.9 & & \\
\hline & Somewhat satisfied & 42 & 27.6 & & \\
\hline & Satisfied & 28 & 18.4 & & \\
\hline & Very satisfied & 5 & 3.3 & & \\
\hline & Total & 152 & 100 & 2.57 & 1.084 \\
\hline & Mean Score & & & 2.78 & 1.115 \\
\hline
\end{tabular}

Source: Field Survey, 2018

satisfied with some of the services offered by NHIF while declining others as not being satisfactory. NHIF members would desire if the scheme covers all services required for their healthcare and include a satisfactory number of dependants who depend on them. The scheme can re-think on how to skyrocket its services to beneficiaries so as to meet beneficiaries' expectations. The previous study by Semkiwa, (2009) found that beneficiaries perceived healthcare offered under NHIF as unsatisfactory giving reasons for limited interaction, timeliness, and atmosphere.
Globally, health insurance is regarded as a device which can trigger countries to achieve the global agenda for universal health coverage. For these reasons, the Tanzania government especially the ministry of health and social welfare on under which NHIF belongs must find the way to upgrade services benefited under the Fund. Following the recommendations of World Health Organization (2014) such as widening priority services to tame out-ofpocket payment, and ensure availability of services such as diagnostic services, medical procedures, essential medicines, palliative 
care, and preventive services at all levels of the healthcare system.

The study which was conducted by Kumburu (2015) portrayed NHIF beneficiaries arguing that services offered are low compared to healthcare provided to out-of-pocket patients. The reports showed that pay by cash patients receive better services compared to NHIF members by being attended first, enjoy better relation with healthcare workers, better access to healthcare, perceive better the attitude of healthcare workers, spend shorter time at the hospital. This variation trigger NHIF members to believe that NHIF needs to improve healthcare offered to beneficiaries so as to be on the same level with non-NIHF members. In addition, Mlimbwa (2011) observed that $48 \%$ of the respondents couldn't have joined NHIF if it wasn't compulsory for public servants. This means that they could have opted for other health payment mechanism such as out-ofpocket payment or joining private insurance. The reasons were given for not willing to join NHIF ranges from the unkindness of NHIF accredited health providers, limited benefit packages, low coverage of NHIF services, and high rate of contribution. The Citizen (2017) reported that there are 23 public institutions whose employee are not registered as beneficiaries of NHIF as they purchased health insurance package from the private insurer. The institutions were urged by the parliament to register their member as NHIF beneficiaries. This gives evidence that NHIF beneficiaries perceive services offered under the scheme as low and wish to subscribe to private insurance for more quality healthcare.

\section{Challenges facing the Scheme}

The study established four factors so as to examine to what extent beneficiaries perceive them as challenges impeding NHIF operations. The variable on this part included: budget constraints, awareness of NHIF services, corruption and embezzlement, and acceptance of the scheme by the public.

\section{Chart 1.}

Presents the findings of respondents' perception of the challenges facing the scheme since they were subscribed to it.

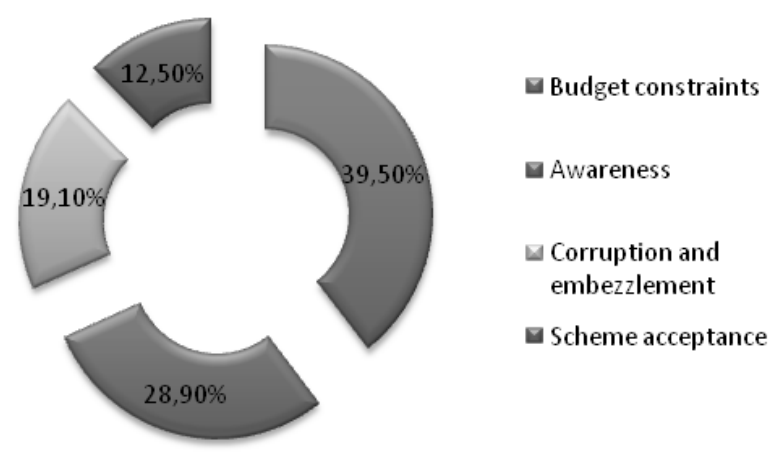

Source: Field Survey, 2018

For budget constraints, it was perceived by the respondents to be the most critical challenge hampering quality services. The score for this factor was $60(39.5 \%)$ reported the case to be most devastating for the scheme to reach most of its goals. These findings cast doubt whether the scheme really meets its goals and that of the stakeholder especially in ensuring that accredited health facility gets their payment on time. However, the findings on this factor are consistent with other studies previously conducted on this topic such as (Kibanga, 2007; Mershed and Reinhard, 2012; Marwa, 2016; National Audit Office (2008). The findings from these past studies found a huge discrepancy on the financing of the scheme which needs to be tackled so as to ensure the sustainability of the scheme.

Secondly, awareness of the scheme services was reported by $44(28.9 \%)$ of the respondents. This reveals that the general public has limited information about NHIF services and probably the reasons why the scheme is still swaying to reach citizens in the informal sector. The awareness of the services offered by the scheme is critical and therefore strategy need to be set in place so 
as more information is apprehended by the consumer. Findings by Nyorera (2015) and Cutler/Zeckhauser 2000 in Osei-Akoto, 2003) both discussed how information about NHIF services affects people deciding whether to join or not. Despite the fact that NHIF in Tanzania context is currently compulsory for public servants this doesn't give an excuse for underrating the power of awareness for quality healthcare.

Thirdly, the study investigated the acceptance of the scheme by the general public. $29(19.1 \%)$ of the respondents perceived it to be a challenge affecting healthcare delivery. The success of any form of financing for healthcare stems from the acceptability of other concerning parts such as consumers and accredited health facility. On this factor, NHIF management needs to struggle so as to strengthen the acceptability of the scheme as being effective devices for financing healthcare. This can be conducted by increasing awareness and also increasing benefit packages to mean healthcare services covered by the scheme so people can identify the worthiness in it.

Lastly, corruption and embezzlement were ranked last by scoring the lowest in the distribution of the participant's responses. Only $19(12.5 \%)$ of the respondents perceived it to be the challenge hindering the scheme performance. On the other hand, corruption has been reported in other studies as a challenge hampering the delivery of quality healthcare across the country and other parts of the world. Findings by (Marwa, 2016; Abdulrahman \& Maarufat, 2017) in Tanzania and Nigeria respectively reported the existence of corruption as being pervasive and intractable. Similarly, Sparrow (1996) devoted discussing the question of corruption in the US healthcare systems and found that with the use of sophisticated technology to manage the transaction, corruption has spoiled the delivery of quality care in the country.

\section{Limitations of the Study and Recommendations}

The study is limited in one region Dar es Salaam region, Tanzania which makes difficult to replicate the same findings to other regions with diverse context like that found in Dar es Salaam. It is also beneficiaries centered satisfaction assessment as it doesn't involve other cadres relevant to the healthcare system in a country such as examining physicians and nurses satisfactions. Additionally, the study didn't collect opinions from NHIF management to explore their opinion on the services offered and its perceived challenges.

Also, the study didn't observe the level of satisfaction for beneficiaries depending on the health facility they attend. NHIF has accredited various health facilities to provide healthcare to its beneficiaries from a private hospital, public hospital, and Faith-based hospital. The distinction on how each category can affect patients' satisfaction is not well established as patients may have various perceptions depending on whether they attend the private, public or faith-based facility.

It's recommended from this study that the government of Tanzania need to set clear policies to control factors that interfere beneficiaries' satisfaction on the quality of healthcare given under NHIF especially waiting time. It can be done by promoting learning and development vacancies for healthcare providers across cadres so as they master their job to be more effective and efficient. The study adds that the Ministry of Health and Welfare initiate a policy framework that outlines the effectiveness of each factor for each accredited healthcare facility control mechanism so as to meet patients' needs. Addressing the problem of healthcare workers by creating synergy between government, Ministry of health and social welfare, NHIF and accredited hospitals to have a common understanding on how big the problem is and how each part can play based on need assessment to be conducted. Furthermore, committed leadership is required to tackle the 
problem of budget constraints by increasing investment on health so as to produce positive impact, escalate public acceptance of the scheme through education and, lastly, tight all slacks that stimulate corruption behavior in the healthcare system in the country. The scheme should also rethink of increasing the number of dependants which is regarded to be low so as to meet member desire.

\section{Conclusion}

The study was conducted in Dar es Salaam region, Tanzania involving one public institution namely National Identification Authority (NIDA). The number of 152 respondents deliberately partake this study by responding to a Google-form questionnaire. The number of male respondents was greater than their counterpart female and this happened haphazardly during sampling. Majority of the respondents were below the age of 40 which indicate most of the youth and energetic individuals are given the chance to perform tasks in the public sector. All respondents were literate with essential information about NHIF and its offered services which increase the credibility of the findings reported in this study.

It should benoted that this study considers very dissatisfied and somewhat dissatisfied as falling in the same category of unsatisfactory healthcare offered under NHIF. On the other hand, considers somewhat dissatisfied, satisfied and very satisfied as falling in the same aspect of satisfactory healthcare services given under NHIF. Generally, the results indicate that beneficiaries were satisfied with many aspects of the healthcare services offered under the scheme. However, the study found unsatisfactory results on few statements such as a number of dependants, the range of diseases covered, time for treatment intervention, time to wait for diagnostic tests, an appointment with specialists, time to retrieve files. Hence calling for special attention to improve healthcare delivery under NHIF especially considering the aspect of time a patient ought to spend to get service at an accredited healthcare facility.

On the other hand, the study has made an important discovery on the challenges hampering the quality of healthcare under NHIF. It's important to note that beneficiaries (respondents) perceived budget constraints as being the critical challenge NHIF faces in the course of providing healthcare to beneficiaries. It has been in conformity with other scholarly works that report that NHIF delays reimbursing accredited facility and members for the services given. Kumburu (2015) reports that claim payment can take up to three months before being completed which undermines access to healthcare by NHIF members.

Other challenges chronologically include awareness about NHIF services which was ranked number two indicating that members are not well informed on the services received under NHIF. It was then followed by acceptance of the scheme being ranked third. Finally, corruption and embezzlement were ranked the last revealing that beneficiaries rarely encounter the problem of corruption while accessing healthcare under NHIF. It is the responsibility of NHIF and accredited health facility to tight all available loophole that allows corruption and embezzlement to prevail.

\section{References}

Abdulrahman, S. A., \& Maarufat, O. O. (2017). An assessment of the level of implementation and impact of the National Health Insurance Scheme (NHIS) on the Health Care System in Yobe State, North-Eastern Nigeria. IOSR Journal of Dental and Medical Sciences (IOSR-JDMS), 16(5), 60-67.

Anderson, R. E. (1973). Consumer dissatisfaction: The effect of disconfirmed expectancy on product performance. Journal of Marketing Research, 10(1), 38-44.

Bayarsaikhan, D., \& Lurent, M. (2016). Health financing issues and reforms in Africa. 
International Journal of Healthcare, 2(2). doi: 10.5430/ijh.v2n2p37

Kibanga, C. J. (2007). The contribution of NHIF in improving the provision of health services: The case study of Kibaha District in Coast Region - Tanzania (Unpublished master's thesis, 2007).

Kumburu, P. N. (2015). National Health Insurance Fund (NHIF) in Tanzania as a tool for improving universal coverage and accessibility to health care services: Cases From Dar Es Salaam - Tanzania (Unpublished master's thesis, 2015).

Lavy, V., \& Alderman, H. (1996). Household response to public health services: Cost and quality tradeoffs. The World Bank Research Observer, 11(1), 3-22.

Marwa, C. W. (2016). Provision of national health insurance fund services to its members; members; pain or gain?. Unified Journal of Sport and Health Science, 2(1), 001- 006.

Mcintyre, D., Bertha, G., \& Gemini, M. (2008). Beyond fragmentation and towards universal coverage: Insights from Ghana, South Africa and the United Republic of Tanzania. Bull World Health Organ, 86(11), 871-876.

Mershed, M.,\& Reinhard, B. (2012). Healthcare financing in Syria: Satisfaction with the current system and the role of national health insurance-a qualitative study of householders' views. The International Journal of Health Planning and Management, 27(2), 167-179.

Ministry of Health and Social Welfare (MOHSW). (2013). Human resource for health country profile - Tanzania. Tanzania: Government Publisher.

Mlimbwa. (2011). The Assessment of members' attitude towards National Health Insurance Fund (NHIF) services: A case of Dar Es Salaam - Tanzania (Unpublished doctoral dissertation, 2011).
Msimbe, B. (2005). Impact of HIV/Aids Pandemic on National Health Insurance Fund Operations. GUARDIAN. Dar es Salaam.

Mtei, G. J. (2005). Analysis of the National Health Insurance Fund in Tanzania: Could out-ofpocket be a better option? (Unpublished doctoral dissertation, 2005).

Mtei, G. J., \& Josephine, B. (2010). An assessment of health care financing progressivity in Tanzania. Dar es Salaam: Ifakara Health Institute.

Mtei, G. J \& Makwaia, S. (2014). Universal Health Coverage: Tanzania. (Working paper). Uganda.

Mwinuka, B., \&Aggrey, R.M.K. (2016). Assessment of the level of satisfaction between beneficiaries of Sokoine University of Agriculture Community Health Fund (SUACHF) and beneficiaries of the National Health Insurance Fund (NHIF) in Morogoro Region. Imperial Journal of Interdisciplinary Research (IJIR), 2(10), 1063-1069.

National Audit Office. (2008). A performance audit report on the management of primary health care: A case study of health centers. Dar es Salaam, Tanzania: National Audit Office.

National Bureau of Statistics (NBS), Ministry of Health and Social Welfare (MoHSW), Office of the Chief Government Statistician (OCGS) \& ICF International (2016). Tanzania Service Provision Assessment Survey 2014-2015. Dar es Salaam, Tanzania, and Rockville, Maryland, USA: MoHSW, NBS, OCGS, and ICF International.

Nyorera, E.N,\& Walter, O. (2015). Factors affecting the uptake of national hospital insurance fund among informal sector workers: A case of Nyatike Sub-County, Kenya. International Journal of Economics, Commerce and Management, 3(3), 1-18.

Olson, J., \& Dover, P. (1979). Disconfirmation of consumer expectations through product 
trial. Journal of Applied Psychology, 64(2), 179-189.

Osei-Akoto, I. (2003, April 7-9). Demand for voluntary health insurance by the poor in developing countries: evidence from rural Ghana. Paper presented at the conference on Staying Poor: Chronic poverty and development policy, IDPM. in the UK, Manchester.

Prabhakaran, S. \& Arin, D. (2017). An actuarial study of the proposed single national health insurance scheme in Tanzania. A Summary Brief Policy November 2017.

Semkiwa, M. (2009). Assessment of customer satisfaction on the health service in Tanzania, a case of health centers owned by local governments (Doctoral dissertation, University of Dar es Salaam, 2009). Tanzania: University of Dar es Salaam.

Sparrow, M. (1996). License to steal: Why fraud plagues the American health care system. Boulder, Colorado: Westview Press.
Sugiyono.(2011). Metode penelitian quantitative qualitatif dan R \& D. Bandung: Alfabeta, CV.

The Citizen. (2017). Tanzania: More Tanzanians should have health insurance. Retrieved April 12, 2019, from https://allafrica.com/ stories/201704120461.html.

Thompson, M., Price, C. P. P., \& Van den Bruel, A. (2011). Innovation in Diagnostics and Healthcare: Improving bench to bedside processes for testing. Centre for Monitoring and Diagnosis, University of Oxford Department of Primary Care Health Sciences.

World Health Organization. (2016). Global strategy on human resources for health: Workforce 2030. Avenue Appia: WHO Press, World Health Organization.

World Health Organization. (2014). Making fair choices on the path to universal health coverage: final report of the WHO Consultative Group on Equity and Universal Health Coverage. Geneva: WHO. 